University for Business and Technology in Kosovo

UBT Knowledge Center

UBT International Conference

2015 UBT International Conference

Nov 7th, 9:00 AM - 5:00 PM

\title{
Introduction to Stratospheric Communication Platforms (SCP)
}

Dimov Stojce llcev

Durban University of Technology, ilcev@dut.ac.za

Follow this and additional works at: https://knowledgecenter.ubt-uni.net/conference

Part of the Computer Sciences Commons, and the Digital Communications and Networking Commons

\section{Recommended Citation}

Ilcev, Dimov Stojce, "Introduction to Stratospheric Communication Platforms (SCP)" (2015). UBT International Conference. 88.

https://knowledgecenter.ubt-uni.net/conference/2015/all-events/88

This Event is brought to you for free and open access by the Publication and Journals at UBT Knowledge Center. It has been accepted for inclusion in UBT International Conference by an authorized administrator of UBT Knowledge Center. For more information, please contact knowledge.center@ubt-uni.net. 


\title{
Introduction to Stratospheric Communication Platforms (SCP)
}

\author{
Dimov Stojce Ilcev \\ Durban University of Technology (DUT), Durban, RSA, \\ ilcev@dut.ac.za
}

\begin{abstract}
In this paper are introduced the modern airship techniques and technologies as cost effective solutions of Stratospheric Communication Platforms (SCP). The launch or putting in position the airship is not critical point such as launch of satellite and controlling support services in the creation of space-based communication technology and the most expensive phase of the total system cost. Therefore, with few cost effective remote controlled and solar powered airships can be covered some region or country including urban, suburban and rural areas, mobile, farms and other environments with low density of population. The airship SCP network offers better solutions than cellular radio systems, with greater speed of transmission than even optical modes, roaming will be enhanced without severe shadowing or obstacle problems and disturbances inside of buildings and service will cost less. The SPS mission system is more autonomous and discrete, can be integrated with current satellite and cellular systems, and will be the best solution for rural, mobile transportation and military applications. The SCP airship can be seen well from all positions inside coverage area, because they are overlapping the total coverage and because of elevation angle. In any circumstances mountains, buildings and even trees cannot cause obstructions like to cellular network. For these reasons, there is currently a revival of interest for SCP constellations and application types of various system concepts are being studied.
\end{abstract}

Keywords: SCP, TAO, Airship, Ground Segment

\section{Introduction}

Despite of advances in Wireless and Terrestrial Telecommunications Technology, almost three billion of world populations are living in rural locations are still without any telephone facilities. However, except already developed Fixed and Mobile Satellite Communications Networks, SCP Systems are the newest space technique with top digital transmission technologies for fixed and all mobile commercial and military applications, which include remote and rural solutions. These systems employs unmanned or manned and on solar or fuel energy aircraft and airships carrying onboard payloads with transponders and antennas, providing new technique known as Voice, Data and Video over IP (VDVoIP) service.

The SCP networks are the newest space technique with top technologies for fixed and mobile applications, including military solutions. These systems are using unmanned or manned aircraft and on solar or fuel energy airships and carrying payloads with transponders and antenna systems. With a few very cheap remote controlled and solar powered airships as a better solution, a territory can be covered of some region or country including urban, suburban and rural areas, farms and other environments with a low density of population. However, today there are developed four general telecommunications architectures, which can be used to deliver broadband wireless local loop service to consumers. Two of these architectures are Geostationary Earth Orbit (GEO) and Non-GEO satellite systems and the other two are terrestrial rooftop cellular-like millimeter wave repeaters and stratospheric relay platforms. 
The SCP network offers better solutions than all cellular and wireless systems, with greater speed of transmission than even optical modes, roaming will be better, without shadowing problems and disturbances inside buildings and service will cost less. The SCP mission can be integrated with current satellite and cellular systems; the system is more autonomous and discrete and will be the best for military and all mobile applications. For instance, the Halo Broadband GSPS Millimetre Wavelength (MMW) Network of the Angel Company provides data densities nearly one thousand times higher than proposed satellites, shown on Table 1, while having round trip time delays appropriate for interactive broadband services. Whereas, the delays through satellite network nodes, even through LEO satellite nodes, are too long for many interactive applications, delays are 25 or 1,000 times longer for LEO or GEO then for Halo Networks, respectively. In fact, the Halo comparison parameters are similar to a variety of metropolitan environment spectrum used bands of the Local Multipoint Distribution Service (LMDS) band near $28 \mathrm{GHz}[1,2,3]$.

Table 1. Comparison of Data Density and Signal Delays [2]

\begin{tabular}{|l|l|l|l|l|}
\hline \multirow{2}{*}{ Node Type } & \multicolumn{2}{|c|}{ Node Data Density } & \multicolumn{2}{c|}{ Round Trip Delay } \\
\cline { 2 - 5 } & $\begin{array}{l}\text { Min } \\
\left(\mathrm{Mb} / \mathrm{s} / \mathrm{km}^{2}\right)\end{array}$ & $\begin{array}{c}\text { Max } \\
\left(\mathrm{Mb} / \mathrm{s} / \mathrm{km}^{2}\right)\end{array}$ & $\begin{array}{l}\text { Min } \\
(\mathrm{millisec})\end{array}$ & $\begin{array}{l}\text { Max } \\
(\mathrm{milieu})\end{array}$ \\
\hline LMDS & 3 & 30 & 0.003 & 0.060 \\
\hline Halo & 2 & 20 & 0.10 & 0.35 \\
\hline LEO (Broadband) & 0.002 & 0.02 & 2.50 & 7.50 \\
\hline GEO & 0.0005 & 0.02 & 200 & 240 \\
\hline
\end{tabular}

\section{Airships SCP}

The new airship projects offer cost-effective systems for SCP by using special unmanned and nonfuel solar cell powered balloons with an estimated endurance of several months. In comparison of aircraft and airship systems it is difficult now to say which one will be better for the future reliable SCP. Thus, there are several airships such as: SkyStation Global Network, SkyLARK Network, StratCon (StratoSat) Global Network, TAO Network, etc.

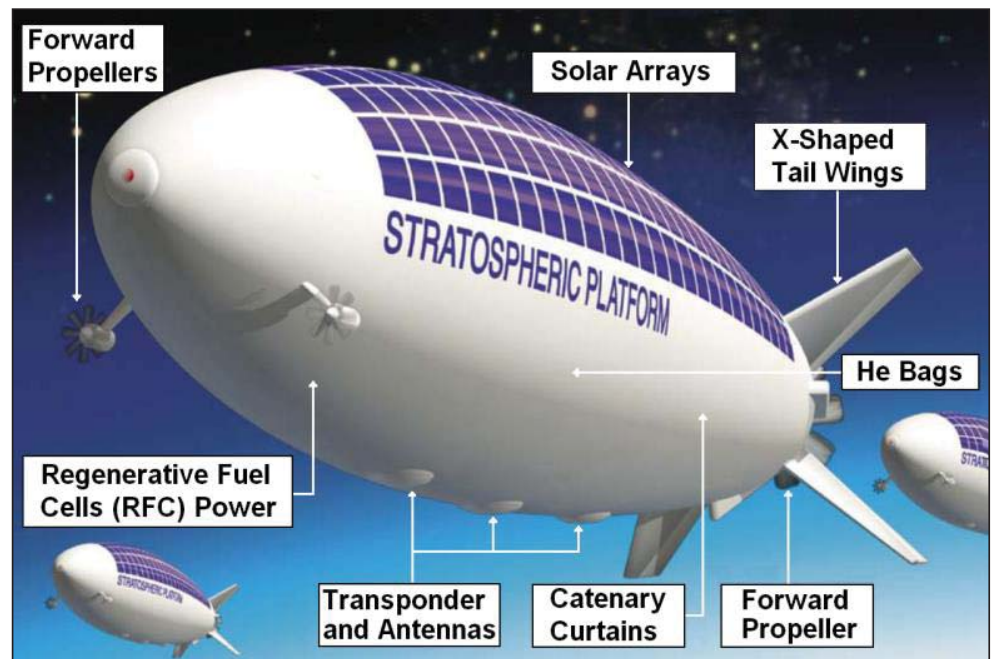

Fig. 1. TAO Airship with Main Components - Courtesy of Webpage: by TAO [3] 


\section{TAO (SkyNet) Network}

A Research and Development program (R\&D) on a SCP airship system is in progress since April 1998. The final goal of this project is to realize the SCP airship platform system, being capable of an acceptable long-duration station-keeping flight at a stratospheric altitude of about $20 \mathrm{~km}$. The achievements will enable advanced wireless fixed and mobile communications, digital direct and relay broadcasting, modern broadband and multimedia transmission, high speed Internet, highresolution observations and monitoring of the remote, rural and global environment. This advanced SCP program is recently promoted in collaboration with the Communications Research Laboratory of Japan (CRL), National Space Development Agency of Japan (NASDA) and Japan Marine Science and Technology Centre (JAMSTEC), including the Telecommunications Advancement Organization (TAO) of Japan.

\subsection{Airship Platform System Description}

The stratospheric platform is an unmanned airship kept at a stratospheric altitude of about $20-25 \mathrm{~km}$ for broadcast and multimedia communications and Earth observation purposes, illustrated in Figure 1. The SCP airship is equipped with corresponding communications payload, observation sensors and other necessary flight equipment. Thus, with the aim of quickly developing an SCP platform has great potential; so many research institutions in Japan began conducting the relevant research work in 1998. The SCP system is designed similar to a satellite space segment as a relay station to receive signals from ground stations using feeder links and to retransmit them to subscribers using service links.

Therefore, an airship platform like a satellite is carrying a payload with corresponding transponders and antenna system. At any rate, the launch of SCP into position is much simpler than putting a satellite into any orbit. After careful preparation in the hanger space, the airship is launched in 4 Ascent phases through the troposphere and Interface location point in the stratosphere and finally, it shifts to the station-keeping position. The recovery phase goes in the opposite direction, namely, the airship is slowly moved from the station-keeping position towards the Interface point and from there descends down to the ground in 4 descent phases. The airship construction has a semi-rigid hull of ellipsoidal shape, with an overall length of about $200 \mathrm{~m}$. Platform is composed of an air-pressurized hull for maintaining a fixed contour and internal special bags filled with the buoyant helium gas. Two air ballonets are installed inside the hull to keep the airship at a required attitude. For a load balance to the lifting force, catenary curtains are connected to the lower rigid platform's keel and are directly attached to the envelope. Propulsive propellers are mounted on both the stem and stern of the airship and tail fins are installed on the rear end of the hull. A solar photovoltaic power system of solar cells and Regenerative Fuel Cells (RFC) is provided to supply a day and night cycle of electricity for airship propulsion. The length of an airship in general is about $250 \mathrm{~m}$ and $60 \mathrm{~m}$ diameter. This is about 4 times as long as Jumbo jet passenger airplanes and so its weight is about 32 tons. However, $50 \%$ of the weight corresponds to those of structures and membrane materials. Hence, solar arrays and fuel batteries, related to the electric power subsystem, are also heavy. And the weight of mission equipment is supposed to be about 1 ton. The necessary condition for an airship to float at a certain altitude is that the gravity and buoyancy forces, which are exerted on the airship, are in a state of equilibrium. When the shape and volume of the airship are supposed to be constant, unlike a balloon, the buoyant force at an altitude of $20 \mathrm{~km}$ becomes about 1/15 that at sea level. Accordingly, a buoyancy of 15 times as much is necessary for equilibrium. Therefore, in order to float a SCP in the stratosphere, it is necessary to make the weight of the airship light and to make the buoyancy as large as possible. Inside the airship there are several internal bags filled with He gas to obtain enough buoyancy [2], [3], [4], [5].

\subsection{Outline of the Tracking and Control System}


In order to operate unmanned SCP airship safely, it is necessary to construct a tracking and control system and establish operational technique on board the platform and on the ground. Based on SCP technologies, appropriate countermeasures can be taken in time regarding observation and prediction of weather situations and monitoring of operational conditions of onboard equipment, and even regarding safety of dangerous atmospheric phenomena or abnormal performances of onboard equipment. At this point, the TAO airship system has to develop adequate TT\&C solutions on board the platform and on the ground as well.

During launch airships can be affected strongly by wind, therefore, when the preliminary decision for launching or recovering of an airship is to be made, it is necessary to predict the weather data, especially wind direction and speed, in advance and estimate whether:

1) The airship deviates from the area, within which the tracking and control system works effectively, and

2) The launch of SCP airship or recovery can be conducted safely.

Based on this proper estimation, a final decision to launch or recover is made safely. After the last checks, the airship is released. It starts to ascend due to the effects of the buoyancy. Near the tropopause, which is the layer between the troposphere and stratosphere, it continues to ascend, being drifted by the jet stream. Finally, the airship arrives in transfer position at an altitude of about $20 \mathrm{~km}$. After this operation, the airship is moved to the geo station-keeping position and the mission operation is started. Once an airship is launched, it can be used for a maximum of three years. Namely, an airship is periodically, about every three years, recovered and the He gas and onboard equipment condition is checked. Moreover, after these routine checks, it is launched again. The life of an airship is supposed to be more ten and even twenty years.

\subsection{SCP Network Coverage}

The main question of the future system is how many airship platforms are necessary to cover all particular territory or country and can this system be global? In fact, a 15 Stratospheric Platform arrangement is necessary to cover all the territory of the Japanese islands for communications and broadcasting systems, under the condition of $22 \mathrm{~km}$ airship altitude with a minimum elevation angle of $10^{\circ}$. A single airship can cover a certain service area independently, so that, for example, the service can be started from an area with a large density of population with the number gradually increased. This possibility of flexible business development is one of the merits of SCP systems. The service area enables that one airship can cover generally depends on certain available numbers of ground Transmitter (Tx), Receiver (Rx), two-way direction antennas, methods of modulation and transmission and many other factors. Otherwise, the final intention of this project is to offer services to other regions and certain countries and if economical and technical evaluations are correct, it will provide global coverage. The concept of the system is very advanced in comparison with similar projects and has almost no disadvantages.

\subsection{Ground Segment Features}

On board the airship there is mission equipment to provide Multimedia and Broadcasting for Fixed and Mobile communications including an Earth observation and Disaster Monitoring System. So, airship is expected to have the following features: 


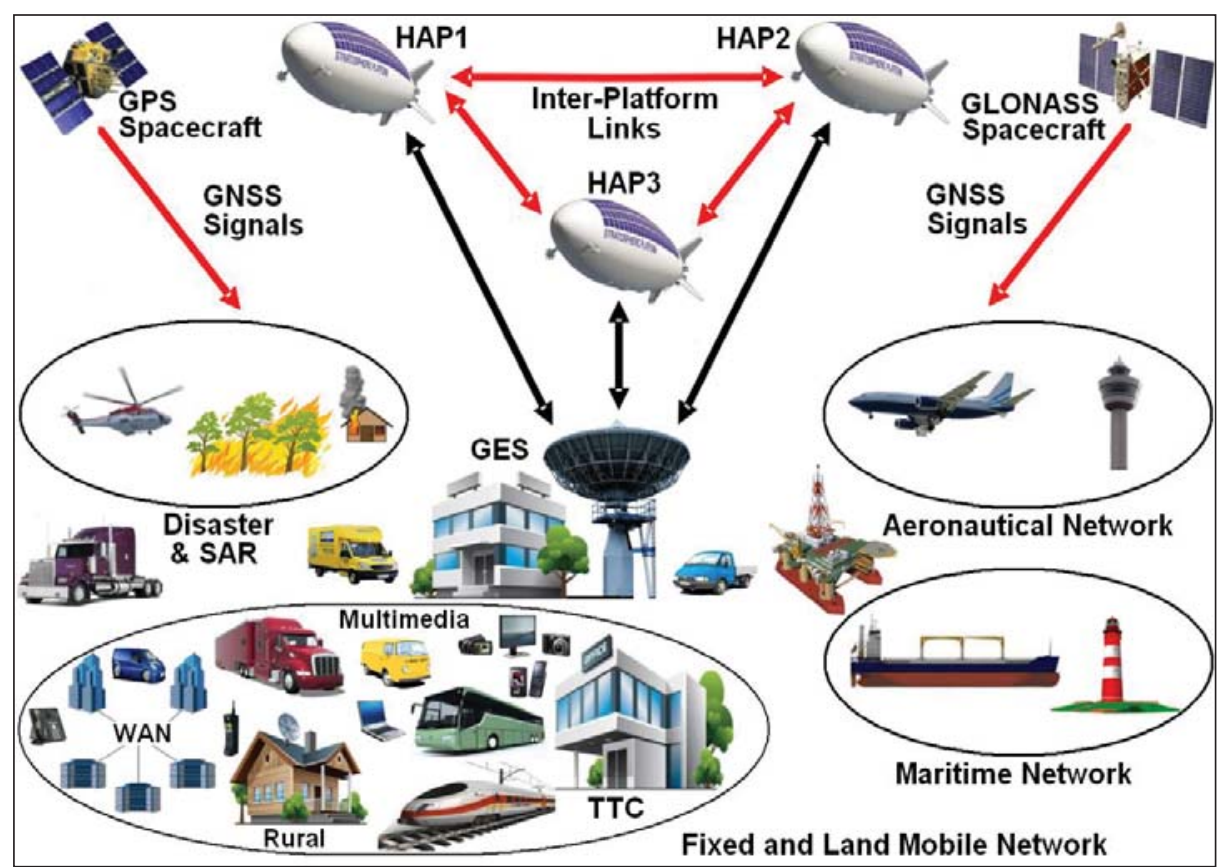

Fig. 2. Fixed and Mobile Communication Network via SCP- Courtesy of Book: by Ilcev [2]

1) Broadband communications and broadcasting are possible with small-sized and very low-power terminals, because of much shorter propagation distances compared with satellite systems.

2) High-quality, reliable and very cost-effective communications and broadcasting are possible with a smaller number of ground stations, due to significantly better line-of-sight conditions, less waveblocking and multi-path effects compared with existing ground systems.

Meanwhile, compared with satellite systems, the propagation distance is shorter by about 1/1800. Consequently, as Electro Magnetic (EM) radiation propagation losses and delay distortions become much smaller, broadband communications and broadcasting are possible with smaller sized and lower power fixed and mobile terminals.

3) By establishing interplatform links, high-speed communications and broadcasting networks, comparable to optical fiber systems will be possible including novel communications.

4) Optimum communication configurations links are possible owing to the flexible operations of airship SCP systems, which can enable expansion to a world communications system.

A complete inter-platform links, fixed and mobile broadband multimedia service program with all applications is presented in Figure 2, [2], [4], [6], [7]. 


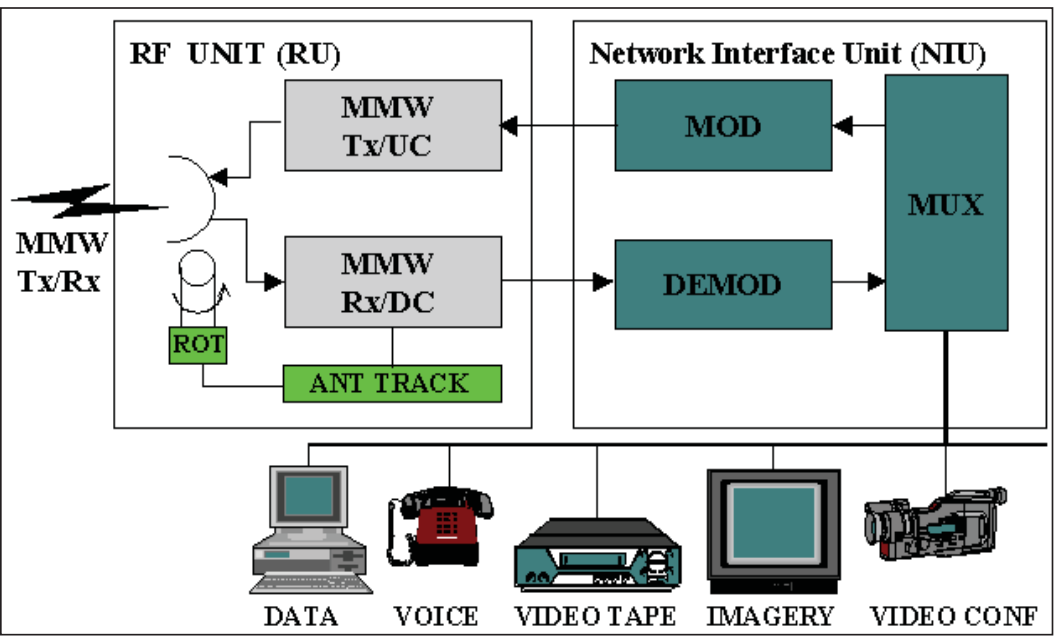

Fig. 3. Functional Diagram of SCP Subscriber Equipment - Courtesy of Book: by Ilcev [2]

Digital TV Broadcasting by SCP will use about 15 CSP to cover all of Japan, where over 10,000 stations are necessary at present. This system will be an advanced communications complement to terrestrial systems at very low cost. Thus, access to for wireless communications systems will be more cost-effective than optical fiber systems. The TAO system will enable much advanced, reliable and better communications for developing countries and will promote spreading (diffusion) in these countries. Emergency communications systems will retain communications links in an emergency by moving into position over the area. In addition, various remote-sensing services will be available for radio wave observations, aerial photographs, Earth and meteorological observations and so on. The CSP System is designed for fixed and mobile multimedia two-way communication system. The ground segment consists of Ground Earth Stations (GES) or Gateways and fixed, semi fixed and mobile terminals, with onboard corresponding auto tracking and focusing antenna systems for all applications, respectively. In fact, fixed ground terminals can be a self-contained portable or office PC configuration with modem, or as an integrated part of an advanced LAN or WAN, laptop, video, fixed telephone set in office or public and mobile or cellular phone equipment.

Mobile systems for Communication, Navigation and Surveillance (CNS) will offer maritime, land, aeronautical and personal applications including GNSS access. At this point, mobile user terminals can be PC/laptop portable or fixed configurations interfaced to the SCP transceiver with adequate antennas or self-contained mobile or portable/in vehicle transceiver units with mobile auto tracking antenna and personal handheld terminals with built-in antenna.

In Figure 3 is shown block diagram of prototype for fixed and mobile SCP equipment and their services.

Maritime SCP equipment and system will provide two-way commercial, distress, emergency and safety communications for ships, fishing and other boats integrated with GEO and GNSS systems. In the framework of this service, there will be additional activities like buoy and lighthouse control, marine pollution, investigation, warnings and Search and Research (SAR) missions.

Land mobile equipment and systems will provide services for all kinds of vehicles like trains, buses, trucks and cars, including personal mobile units, cellular service and emergency communications for natural disasters, which can be enhanced with equipment for tracking and navigation facilities. The SCP has to substitute or integrate current cellular systems.

Aeronautical mobile equipment and systems will provide commercial, safety and distress service for all kinds of aircraft integrated with GEO, GPS and other Global Navigation Satellite Systems (GNSS) to provide CNS service. 
The broadcasting system using the SCP airship constellation will provide: 1) digital broadcasting; 2) complementary terrestrial digital broadcasting to fixed/mobile stations; 3) terrestrial rebroadcasting programs; 4) relay broadcasting of HDTV including radio programs; 5) movable broadcasting on demand, using mobile equipped stations; 6) broadcasting for limited suburban regions, isolated islands, rural and remote places; 7) field pickup from the SCP; and 8) emergency news and observations [2], [3[, [4], [8].

\subsection{Electric Power and Motion of Airships}

Unmanned SCP airships are maintained in the stratospheric zone constantly at an altitude of 20 to 25 $\mathrm{km}$ above commercial flights, where the winds, flow and other meteorological conditions are calm. The mean temperature is -60 to $-50^{\circ} \mathrm{C}$ and the atmospheric pressure is about $50 \mathrm{hPa}$. The altitude of $20 \mathrm{~km}$ is about 60 times higher than the Tokyo TV Tower, so better Lines-of-Sight (LoS) are obtained. However, multi-path effects will be significantly reduced in most areas because of higher elevation angles. There are no clouds in the stratosphere, so perfectly clean solar energy can be used without atmospheric pollution. The concept of SCP airship launch and recovery features an upwind orientation of the airship heading, assuming limited wind speed at the ground surface for takeoff and landing. In additional, for ascents and descents, the airship heading and position should be kept always in an upwind direction, while non-powered flights should require only the buoyant lift into the jet stream.

Stratospheric platforms do not use any fuel for motion, so the only necessary energy is supplied by electric power, obtained from solar cells. The wide part in the graphic of an airship's topside is the solar cell array. Solar cells can supply clean energy without $\mathrm{CO}_{2}$ gas generation, so that it is said to be kind to the Earth and is an ideal form of energy. Only electric power of about $200 \mathrm{~kW}$ is necessary for stratospheric platforms and it is used for the following reasons:

1) To rotate propulsive propellers and supply electric power to the various positioning and attitude controlling systems for station keeping.

2) To operate the on-board payload for mission of communication, broadband and Earth observation systems are necessary about $10 \mathrm{~kW}$.

3) To charge the fuel battery in the daytime and to use it at night, when no solar electric power is obtained. 
The position of an airship is as stationary same as a GEO satellite. Namely, as the airship is used as a platform for communications and broadcasting, it is necessary for it to be almost stationary, like a broadcasting satellite.

Meanwhile, the position of the airship cannot be permanently stationary because of affects from different parameters, which have an influence on the moving range. At this point, it is necessary to provide permanent control of platform moving and when necessary to correct it's position using station-keeping correction motors with forward and rear propellers.

Consequently, as the maximum wind speed is sometimes over $20 \mathrm{~m} / \mathrm{sec}$ at altitudes of 20 to $22 \mathrm{~km}$, it will be very difficult for the airship to be controlled as strictly as geostationary satellites. The moving range of a stratospheric platform is very slow and in such a way requirements of station keeping are within a radius of $1 \mathrm{~km}$ in the horizontal plane and $+/-1 \mathrm{~km}$ in the perpendicular direction and under this condition the design and fabrication of onboard equipment is considered.

A receiving antenna on the ground is set with the bore sight (the axis of the antenna beam) to the airship, so that the maximum receiving power can be obtained. If the position of the airship is changed, the receiving power decreases.

The airship is controlled so as to keep the position as stable as possible. For example, for a $20 \mathrm{~cm}$ diameter antenna, a position change of $600 \mathrm{~m}$ induces $3 \mathrm{~dB}$ or $50 \%$ power loss. This tendency depends upon the antenna size and operational frequency. In this instance, the larger an antenna radius or the higher the frequency, the receiving power becomes less and vice versa. Accordingly, to satisfactorily solve these receiving problems, an automatically pointing corresponding adjustable antenna is being considered and in this way, it is necessary to develop a low-cost and small-sized antenna with automatic tracking system [2], [3], [4].

\section{Conclusion}

There are several unique attributes that allow modern SCP constellation, either aircraft or airships, to offer low-cost broad array service:

1) The SCP infrastructures do not require launch vehicles, they can move under their own power throughout the world or remain stationary, and they can be brought easily down to Earth surface after several months of mission, refurbished and re-deployed without service interruption.

2) With only several SCP airships units is possible to provide regional or local countrywide coverage, while with infrastructure of interplatform optical links between nearby SCP airships is possible to enlarge coverage and enhance service.

3) Every SCP is independent and autonomous for dedicated service area, so once a platform is in right position, it can immediately begin delivering service to its coverage area without the need to deploy a global constellation of platforms to operate. This attribute is very important for rural, mobile and military applications.

4) The altitude enables the SCP system to provide a higher frequency reuse between nearby platform and higher capacity than other wireless systems.

5) Located in the stratosphere 20 to $25 \mathrm{~km}$ above the Earth, each SCP is acting as the very low orbiting satellite, providing high density, capacity and speed service with low power requirements and no latency to entire urban and rural areas.

6) The inexpensive SCP and Gateway stations make it the lowest cost wireless infrastructure per all subscribers conceived to date. The flexibility, reliability, enhanced capabilities and its low-cost will revolutionize telecommunications.

7) Joint venture private companies, government and other authorities located in each country will control the SCP configurations serving their region to ensure the best service offerings tailored to the local market.

8) All types of SCP missions are environmentally very friendly, because most of them are powered by solar technology and non-polluting fuel cells.

9) The SCP airship provides all subscribers with short paths through the space and unobstructed free of shadowing LOS. With very small antenna, transceivers and low power requirements, the SCP system allows for a wide variety of fixed, mobile and portable user terminals to meet almost any service need including distress, commercial and military applications. 


\section{References}

1. Aragón-Zavala A., "High Altitude Platforms for Wireless Communications", Wiley, Chichester, 2008.

2. Ilcev D. S. "Global Mobile CNS", DUT, Durban, 2011.

3. TAO, "Stratospheric Platforms", Tokyo, 2006.

4. Grace D. and Mohorcic M., "Broadband Communications via High-Altitude Platforms", Wily, Chichester, 2011.

5. Tozer T.C. and Others, "High-altitude Platforms for Wireless Communications", Electronics and Communication Engineering Journal, 2001.

6. Miura R. and Others, "Experiments on IMT-2000 Using Unmanned Solar Powered Aircraft at an Altitude of 20 km", IEEE Transactions on Vehicular Technology, Vol. 54, No. 4, July 2005.

7. Ilcev D. S., "Stratospheric Communication Platforms (SCP) as an Alternative for Space Program", AEAT Journal, Emerald, Bingley, 2011.

8. Antonini M. and Others, "Stratospheric Relay: Potentialities of New Satellite-high Altitude Platforms Integrated Scenarios", IEEEAC, 2003. 